Historia i Polityka

Półrocznik poświęcony myśli politycznej i stosunkom międzynarodowym

Nr $9(16) / 2013125-130$

DOI: http://dx.doi.org/10.12775/HiP.2013.008

Joanna Rak (Uniwersytet Mikołaja Kopernika w Toruniu)

\title{
Mariusz Kubiak \\ Kulturowe uwarunkowania obronności państwa Siedlce 2012, ss. 369
}

Słowa klucze: Mariusz Kubiak, uwarunkowania obronności państwa, kultura a bezpieczeństwo, Joanna Rak

B rakuje w polskojęzycznej literaturze z zakresu bezpieczeństwa narodowego prac poświęconych bezpieczeństwu kulturowemu. Zapoznając się z literaturą obcojęzyczną z tegoż obszaru ${ }^{1}$ można za-

1 Por. np. C. Johnson, B. Kirwan, T. Licu, The Interaction between Safety Culture and Degraded Modes: A Survey of National Infrastructures for Air Traffic Management, Risk Management 2009, vol. 11, nr 3/4, s. 241-284; M. Schafer, Cooperative and Conflictual Policy Preferences: The Effect of Identity, Security, and Image of the Other, Political Psychology 1999, vol. 20, nr 4, s. 829-844; T. C. Davis, Revisiting Group Attachment: Ethnic and National Identity, Political Psychology 1999, vol. 20, nr 1, s. 25-47; M. D. Voss, J. M. Whipple, D. J. Closs, The Role of Strategic Security: Internal and External Security Measures with Security Performance Implications, Transportation Journal 2009, vol. 48, nr 2, s. 5-23; K. P. Parboteeah, J. B. Cullen, Social Institutions and Work Centrality: Explorations beyond National Culture, Organization Science 2003, vol. 14, nr 2, s. 137; G. Feldman, Culture, State, and Security in Europe: The Case of Citizenship and Integration Policy in Estonia, American Ethnologist 2005, vol. 32, nr 4, s. 676-694; D. Arase, Non-Traditional Security in uważyć, iż w przypadku rodzimych opracowań wskazane zagadnienia są nierzadko i niesłusznie bagatelizowane lub pomijane. Luki tej nie wypełniła niestety również najnowsza monografia autorstwa Mariusza Kubiaka, pt. „Kulturowe uwarunkowania obronności państwa”, który - na co wskazują poczynione we wstępie do książki uwagi - celował w eksplikacji oraz uzasadnieniu wpływu zespołu uwarunkowań kulturowych na stan obronności państwa. O ile już sam fakt weryfikowalności wpływu wzbudza wątpliwości, co do efektu

China-ASEAN Cooperation: The Institutionalization of Regional Security Cooperation and the Evolution of East Asian Regionalism, Asian Survey 2010, vol. 50, nr 4, s. 808-833; S. Bislev, Globalization, State Transformation, and Public Security, International Political Science Review/Revue internationale de science politique 2004, vol. 25, nr 3, s. 281-296; S. Ilcan, L. Phillips, Governing Peace: Global Rationalities of Security and UNESCO's Culture of Peace Campaign, Anthropologica 2006, vol. 48, nr 1, s. $59-71$. 
analiz, to w przekonaniu o fiasku aspiracji autora całkowicie utwierdzają poczynione założenia metodologiczne.

$\mathrm{Na}$ początku trzeba zwrócić uwagę na opis założeń metodologicznych przy wykorzystaniu pojęć skrajnie nielogicznych oraz pleonazmów ${ }^{2}$ np.: „Wciąż kształtuje się nowy, wielobiegunowy ład świata, w którym system międzynarodowy, na skutek wszechogarniających procesów globalizacyjnych, staje się coraz bardziej współzależny i powiązany" ". Występują one nawet w pierwszym zdaniu „hipotezy roboczej”: „Po rozpadzie bipolarnego podziału świata w środowisku szeroko rozumianej obronności i bezpieczeństwa, coraz większego znaczenia nabrały inne, niż tylko polityczne i militarne uwarunkowania" ${ }^{\prime 4}$. Uderzający jest także, dobrze widoczny w przywołanych przykładach, brak precyzji w sferze zastosowania pojęć. Obniża on bowiem jakość pracy.

Wątpliwości wzbudza również fakt, iż autor sformułował jeden główny problem badawczy i osiem szczegółowych problemów badawczych oraz tylko jedna „hipotezę roboczą". Nie są one przy tym kompatybilne, w związku z czym nie ma uzasadnienia dla tego zabiegu. M. Kubiak wskazał następnie, że: „Zarysowany w temacie obszar dociekań naukowych wymagał bowiem przeprowadzenia badań z zakresu wielu dziedzin i dyscyplin naukowych: nauk wojskowych (a obecnie nauk o obronności oraz nauk o bezpieczeństwie), stosunków międzynarodowych, nauk politycznych, kulturoznawstwa, socjologii, a nawet filozofii. Tak więc, uwzględniając szeroki i wieloaspektowy obszar badań

\footnotetext{
2 Zob. np.: R. Bäcker, Nietradycyjna teoria polityki, Toruń 2011, s. 83.

3 M. Kubiak, Kulturowe uwarunkowania obronności państwa, Siedlce 2012, s. 7.

4 Ibidem, s. 10.
}

zastosowano następujące podejścia: systemowe, instytucjonalne, funkcjonalne i normatywne (prawne), które w trakcie badań traktowano elastycznie, dążąc, z jednej strony, do ich wzajemnego uzupełnienia się, a z drugiej zaś, do poszerzenia istniejących już perspektyw badawczych" ${ }^{5}$. M. Kubiak w żaden sposób nie wyjaśnił jednak na czym polegało użycie tychże podejść.

Po redundancji założeń, autor wskazał, iż: „Podstawowym założeniem przyjętym $\mathrm{w}$ ustanowionym postępowaniu metodologicznym była dążność do jak najbardziej adekwatnego, wobec głównego i szczegółowych problemów badawczych, wyboru metod badawczych" ${ }^{6}$. W ogóle nie wspomniał nawet o technikach i narzędziach badawczych, których dobór warunkuje rezultat procesu badawczego. Natomiast dobór metod uzasadnił w sposób następujący: „Ponieważ rozprawa nosi głównie charakter teoretyczny, najczęściej wykorzystywano w niej najbardziej uznane i sprawdzone metody wnioskowania naukowego, czyli indukcję i dedukcję, ale również inne metody badawcze: analizę oraz syntezę, analogię i abstrahowanie. Warto podkreślić, że szczególnie wiele korzyści poznawczych przyniosło przede wszystkim szerokie zastosowanie analizy literatury przedmiotu"' Uwagi te opatrzył autor przypisem odsyłającym czytelnika do innych opracowań, aby ten poczytał samodzielnie na temat tych metod badawczych. Warto dodać, że w jego ramach umieścił tytuły losowo dobranych podręczników z zakresu metodologii, nie wskazując jednak numerów stron. Pomimo to, w kolejnym akapicie uczony, podjął się krótkiego ich omówienia, wskazując m.in., że: „Metoda analizy literatury

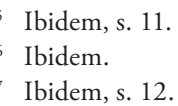


przedmiotu okazała się zasadniczą metodą empiryczną zastosowaną $w$ dociekaniach badawczych. Posłużyła ona przede wszystkim do pozyskiwania w miarę holistycznych informacji na temat istoty, charakteru i cech zespołu uwarunkowań kulturowych oraz młodej dyscypliny naukowej - nauk o obronności, w ich będącym wciąż w początkowej fazie rozwoju, teoretycznym wymiarze" ${ }^{\text {" }}$ Z każdego opisu wynika uzasadnienie jakiegoś zakresu słabości monografii, np. - wg autora - dyspozycja abstrahowania polega na możliwości pomijania dowolnych kwestii $w$ ramach badania, a syntezy - na traktowaniu dowolnych skojarzeń jako naukowych?.

Trudno także znaleźć uzasadnienie dla enumeratywnie wymienionych we wstępie książek. M. Kubiak stwierdził, iż jest to literatura przedmiotu. Niemniej większości z przywołanych dzieł nie wykorzystał w swej pracy. Referencje do nich sprowadzily się zatem do wymienienia w tekście głównym pierwszej litery imienia i nazwiska autora lub redaktora książki, a czasami przy tym miejsca i daty wydania. Zabrakło także wyjaśnienia faktu, dlaczego $\mathrm{w}$ niektórych przypadkach zostały one podane, a w innych nie. Do części z nich dołączone zostały nieujednolicone zapisy bibliograficzne w przypisach - M. Kubiak w sposób arbitralny wybrał, do których książek dopisać wydawnictwo, a do których nie. Brakuje również wskazań stron do poszczególnych publikacji, co zresztą jest normą dla całości opracowania. Nie jest także łatwo odbiorcy wskazać kryterium doboru czy selekcji tej literatury, sam zaś autor tego niestety nie dokonał.

M. Kubiak zarówno we wstępie, jak i w kolejnych rozdziałach opracowania,

\footnotetext{
8 Ibidem, s. 13.

9 Ibidem.
}

wielokrotnie odwołał się do badań dotyczących bezpieczeństwa kulturowego, nie podając ani ich autora, ani źródła, np.: "Z przeprowadzonych badań i analiz wynika, że w Polsce do najbardziej prawdopodobnych zagrożeń tego typu mogą należeć: postępujący kryzys tożsamości narodowej; obniżenie poczucia więzi kulturowej między Polakami; ograniczenie suwerenności państwa; wzrost zależności kulturowej i powielanie zachodnich wzorów; spadek środków finansowych przeznaczonych na kulturę i politykę kulturalną"10. Warto przy tym nadmienić, iż trafność doboru typów wskazanych przez autora jest wątpliwa, m.in. z uwagi na ich widoczny przypadkowy charakter, nierozłączność, nieprecyzyjność czy skrajną nielogiczność. Nieodzowne w tym przypadku jawi się krytyczne spojrzenie na przywołaną typologię, którego na kartach książki zabrakło. Przy okazji powoływania się na inne badania, M. Kubiak wskazał również: „Ponadto podkreśla się możliwość rozwoju takich zagrożeń, jak kryzys uznanych systemów wartości, rodziny, autorytetów i więzi międzyludzkich. Najniebezpieczniejsze są jednak zagrożenia skutkujące ewentualnymi spustoszeniami w sferze tożsamości kulturowej, a więc i tożsamości narodowej. Przekładają się one bowiem wprost na deprecjację poziomu świadomości obronnej jednostek i społeczeństwa" ${ }^{11}$. Wynikanie, na które zwrócił uwagę uczony nie jest oczywiste. Jawi się raczej jako trudne do zweryfikowania, w związku z czym trudno przypisać mu walor naukowego. Podobnie nie jest łatwo wyjaśnić wartościowanie zagrożeń czy stronnicze oceny ${ }^{12}$, jak np.: „Charakterystyczna

\footnotetext{
10 Ibidem, s. 8 .

11 Ibidem, s. 8-9.

12 Zob. D. Parisi, F. Cecconi, F. Natale, Cultural Change in Spatial Environments: The Role of Cultural Assimilation and Internal Changes in Cultures, The
} 
dla globalizacji dyfuzja kultur jest zjawiskiem pozytywnym, ponieważ prowadzi do lepszego poznania i zrozumienia różnych kultur"13. W tym przypadku nieodzowne byłyby faktyczne badania, o które autor się nie pokusił. Warto jednak wspomnieć, iż przywołane stanowisko Kubiaka dotyczące konsekwencji dyfuzji kulturowej jako jedno z nielicznych, obecnych na łamach monografii, zostało przez autora - co prawda pokrótce, ale jednak - uzasadnione.

Następnie autor wskazał, że: „Struktura rozprawy została skonstruowana zgodnie z założonymi wcześniej ustaleniami metodologicznymi"14. Tak też $\mathrm{w}$ istocie jest - poszczególne części układają się w nielogiczną całość. Książka składa się z pięciu rozdziałów zatytułowanych kolejno: „Charakterystyka podstawowych kategorii przedmiotowych”, „Obronność w warunkach globalizacji”, „Kulturowe determi-

Journal of Conflict Resolution 2003, vol. 47, nr 2, s. 163-179; J. Henrich, Cultural Transmission and the Diffusion of Innovations: Adoption Dynamics Indicate That Biased Cultural Transmission Is the Predominate Force in Behavioral Change, American Anthropologist 2001, vol. 103, nr 4, s. 992-1013; C. R. Guglielmino, C. Viganotti, B. Hewlett, L. L. Cavalli-Sforza, Cultural Variation in Africa: Role of Mechanisms of Transmission and Adaptation, Proceedings of the National Academy of Sciences of the United States of America 1995, vol. 92, nr 16, s. 7585-7589; A. Mesoudi, A. Whiten, The Multiple Roles of Cultural Transmission Experiments in Understanding Human Cultural Evolution, Philosophical Transactions: Biological Sciences 2008, vol. 363, nr 1509, s. 3489-3501; S. Reichman, S. Hasson, A Cross-Cultural Diffusion of Colonization: From Posen to Palestine, Annals of the Association of American Geographers 1984, vol. 74, nr 1, s. 57-70; L. Becker, R. Diallo, The Cultural Diffusion of Rice Cropping in Cote d'Ivoire, Geographical Review 1996, vol. 86, nr 4, s. 505-528; L. Bélanger, Redefining Cultural Diplomacy: Cultural Security and Foreign Policy in Canada, Political Psychology 1999, vol. 20, nr 4, s. 677-699.

13 M. Kubiak, op. cit., s. 123.
14 Ibidem, s. 19. nanty stosunków międzynarodowych", „Ochrona dziedzictwa kulturowego w polityce polskiej”, „Obronność w kontekście kulturowym”. Tytuły te nie jawią się jednak jako przemyślane, ponieważ $\mathrm{w}$ pewnych zakresach pokrywają się ze sobą, np. drugi dotyczący obronności w warunkach globalizacji oraz ostatni poświęcony obronności w kontekście kulturowym. Trzeba przy tym zaznaczyć, że ich brzmienie nie odpowiada zawartości rozdziałów.

Rozdział pierwszy nie zawiera obiecanych czytelnikowi wyników badań. Autor, na podstawie zacytowanych opracowań, zdefiniował w jego ramach m.in.: obronność, bezpieczeństwo, zagrożenia dla obronności i bezpieczeństwa, kulturę, kulturowość, bezpieczeństwo kulturowe, tożsamość kulturową, globalizację i siły zbrojne. Brakuje krytycznego na nie spojrzenia oraz propozycji autorskich definicji. Niemniej M. Kubiak uzasadnił jakość tegoż rozdziału w sposób następujący: „Takie założenie metodologiczne miało na celu ukazanie w miarę holistycznego środowiska badawczego, w którym następnie analizowano spektrum uwarunkowań kulturowych i ich różnorodny wpływ na obronność" ${ }^{15}$. Trudno jednak przyznać autorowi słuszność w tym zakresie ${ }^{16}$.

Następnie uczony po raz kolejny zdefiniował globalizację oraz opisał jej istotę, a także wskazał na płaszczyzny procesów globalizacyjnych. Pokrótce scharakteryzował wymiary globalizacji: ekonomiczno-gospodarczy, kulturowy, polityczny, informacyjny, ekologiczny i globalną przestępczość zorganizowaną. Zakończył swój wywód

15 Ibidem.

16 Zob. np. P. Strimling, M. Enquist, K. Eriksson, S. A. Levin, Repeated Learning Makes Cultural Evolution Unique, Proceedings of the National Academy of Sciences of the United States of America 2009, vol. 106, nr 33, s. 13870-13874. 
uwagami na temat obliczy procesów globalizacyjnych - po raz wtóry - oraz wojen i konfliktów zbrojnych czasów globalizacji. Nie odnajdzie czytelnik w tym wywodzie rezultatów własnych badań autora.

W trzecim rozdziale, M. Kubiak omówił wybrane w sposób arbitralny i nieuzasadniony, kulturowe determinanty stosunków międzynarodowych ${ }^{17}$. Ograniczył się do lakonicznych zwrotów, takich jak np.: „warto zaprezentować opinię...”18, „wydaje się, iż..."19. Uznanie opinii za naukowe jest jednak w tym przypadku co najmniej kontrowersyjne. Podobnie zresztą jak nielogicznych konkluzji, np.: „Różne plemiona, nawet te zinformatyzowane, będą mieć różne przyszłości, skoro miały różne przeszłości”" ${ }^{20}$ W jego ramach także nie ma nawet części raportu z zapowiedzianych przez autora we wstępie badań.

Rozdział czwarty dotyczy ochrony dziedzictwa kulturowego w polityce polskiej. Autor - odwołując się głównie do dostępnych na polskim rynku wydawniczym opracowań - scharakteryzował „unormowania polityczne i prawne"21. Wymienił i pokrótce opisał instytucje ochrony dobór kultury, przedstawił podstawowe założenia polskiej polityki kulturalnej i podjął próbę nakreślenia istoty zagranicznej polityki kulturalnej Polski. Nie wyczerpał tematów, których eksplikacji się podjął, niesłusznie

17 Zob. np. M. E. Hochberg, A Theory of Modern Cultural Shifts and Meltdowns, Proceedings: Biological Sciences 2004, vol. 271, nr 5, s. S313-S316; J. D. Fearon, Ethnic and Cultural Diversity by Country, Journal of Economic Growth 2003, vol. 8, nr 2, s. 195-222; T. M. Schmitt, Global Cultural Governance. Decision-Making Concerning World Heritage between Politics and Science, Erdkunde 2009, vol. 63, nr 2, s. 103-121.

\footnotetext{
18 M. Kubiak, op. cit., s. 123.

19 Ibidem, s. 127.

20 Ibidem, s. 129.

21 Ibidem, s. 181.
}

pominął ważne źródła, takie jak choćby stenogramy z posiedzeń Sejmu Rzeczypospolitej Polskiej. Również na stronach tego rozdziału M. Kubiak nie zaprezentował wyników własnych badań.

Dziwi oddzielenie ostatniego rozdziału od przedostatniego, np. po zakończonym już wywodzie zamieszczonym w ramach rozdziału czwartego, autor w pierwszym podrozdziale piątego, omówił działalność resortu obrony narodowej na rzecz kultury. Wskazuje to na nieprzemyślaną strukturę monografii. Także w ostatnim rozdziale zabrakło przedstawienia rezultatów autorskich analiz. Dlatego też należy podważyć wiarygodność treści podsumowania: „Przeprowadzone $\mathrm{w}$ dysertacji badania dotyczące wpływu uwarunkowań kulturowych na obronność państwa w wyraźny sposób wykazały ich rosnącą rolę w obecnych czasach" $^{22}$.

Zakończenie pełne jest konkluzji niezwiązanych bezpośrednio z treścią problemów badawczych, sformułowanych we wprowadzeniu, jak np.: „Okazało się, że wbrew przewidywaniom niektórych z głośnych wizjonerów-optymistów, a w tym przede wszystkim Francis'a Fukuyamy, system demokracji liberalnej nie jest doskonałym antidotum na bolączki całego świata"23. Podobnie jak zawartość poszczególnych, kolejnych rozdziałów książki nie są one odkrywcze.

Zrecenzowanej książki nie poleca się zatem czytelnikom zainteresowanym poszerzeniem swojej wiedzy z zakresu bezpieczeństwa narodowego, a ściślej - bezpieczeństwa kulturowego. Przede wszystkim brak na jej łamach dostrzegalnego namysłu nad sensem i funkcjonalnością wykorzystania kolejnych pojęć w celu opisu rzeczywi-

\footnotetext{
22 Ibidem, s. 350.

23 Ibidem, s. 336.
} 
stości politycznej. Wiele zaprezentowanych konstatacji jest nielogicznych. Nie ma również krytycznego podejścia do literatury przedmiotu - zastąpiło go bezrefleksyjne cytowanie dobranych w sposób arbitralny opracowań. Od pierwszych stron książki widoczne jest to, iż jej autor nie przyjął żadnych właściwych kryteriów doboru i selekcji źródeł. Przede wszystkim jednak M. Kubiaka nie odznacza ani znajomość, ani umiejętność stosowania podstawowych zasad metodologicznych. W ogóle nie wyznaczył dla swej pracy pola badawczego. Sformułowane przez uczonego problemy badawcze - główny i szczegółowe nie są kompatybilne z „hipotezą roboczą”. Zabra- kło definicji zmiennych zależnych i niezależnych, prawidłowo dobranych i uzasadnionych metod badawczych. Podkreślić również trzeba całkowitą ignorancję autora względem technik oraz narzędzi badawczych, o których nawet nie wspomniał ${ }^{24}$. Opracowanie autorstwa M. Kubiaka pomimo dumnie brzmiącego opisu na okładce („Rozprawa naukowa nr 116”) nie ma charakteru naukowego, a jego przywołane oraz wyłaniające się z kolejnych fragmentów tekstu słabości powodują, że książka ta nie jest godna uwagi odbiorcy.

24 Por. R. Bäcker, op. cit., s. 11-13. 